\title{
Factors Affecting NCLEX-RN Success in an Associate Degree Nursing Program
}

\author{
Laura Lewicki ${ }^{1} \quad$ Lori Kupczynkski ${ }^{2} \quad$ Chris Cale $^{3} \quad$ Sunddip Panesar-Aguilar $^{3 *}$ \\ 1.Health Sciences, Hillsborough Community College, Florida, USA \\ 2.Riley College of Education, Walden University, Minneapolis, Minnesota, USA \\ 3.College of Rehabilitative Science, University of St. Augustine, St. Augustine, Florida, USA \\ * E-mail of the corresponding author: saguilar@usa.edu
}

\begin{abstract}
An acute nursing shortage currently exists in the United States. It is important for nursing programs to prepare nursing students who are able to pass the NCLEX-RN. The purpose of this study was to determine whether a link exists between nursing student performance in program requirements and ultimate success or failure on the NCLEX-RN. A random sample of the nursing students at one community college who graduated in the calendar years of 2017 and 2018 were the population for this study. This comparative study examined data in existence to determine if there were academic factors relating to failure on NCLEX-RN. Chi-square was used to determine a relationship and phi-coefficient was used to determine the strength of that relationship between dependent and independent variables. A weak to moderate association was found between failure on NCLEX-RN and the independent variables: low score on the science portion of the TEAS test, need to repeat the first medical-surgical nursing course, and less than 850 on HESI exit. Future research should focus on the connection between mathematics scores and success in the nursing program and NCLEX-RN.
\end{abstract}

Keywords: Nursing education, NCLEX-RN pass rates, nursing education readiness, healthcare education, student success.

DOI: $10.7176 / \mathrm{JEP} / 12-30-01$

Publication date:October $31^{\text {st }} 2021$

\section{Introduction}

Nursing school is a challenging journey from meeting entrance requirements, completing the nursing curriculum, and ultimately, to taking the National Council Licensing Exam for Registered Nurses (NCLEX-RN) (Glasgow et al., 2019; Ralph et al., 2019). In spite of the rigorous requirements, the pass rate for first-time test takers for associate degree nursing (ADN) graduates on the NCLEX-RN remains at about $85 \%$ annually (National Council of State Boards of Nursing, 2019). The ability to predict if nursing students are at risk for failure on NCLEX-RN could provide nursing programs with information that could prevent failure on NCLEX-RN. Examining nursing program admission requirements, along with results on predictor exams, may provide insight on the ability to predict if a student is at risk for failure on NCLEX-RN. Identifying commonalities among nursing program graduates that fail NCLEX-RN allows the program the opportunity to explore strategies to prevent failure on NCLEX-RN.

Scholars and hospital administrators are anticipating a major nursing shortage to occur and have been predicting a shortage since the beginning of this century (Benner et al., 2010). Many factors contribute to this shortage, including an aging and ailing population (Snavely, 2016). This aging and ailing population require more nurses and other healthcare providers in the hospital, in long-term care, and at home (Snavely, 2016; Wessel, 2017). There is pressure on nursing programs to educate and graduate nursing students who can pass the NCLEX-RN and are work ready to lessen the impact of the nursing shortage (Quinn et al., 2018; Randolph, 2016; Robert, 2018).

Upon completion of an approved nursing program, nursing graduates must pass the NCLEX-RN to become licensed as a registered nurse (Quinn et al., 2018; Randolph, 2016; Robert, 2018). The NCLEX-RN is a national examination prepared by the National Council of State Boards of Nursing (NCSBN) (National Council of State Boards of Nursing [NCSBN], 2018).

In 2013, the passing standard was raised, resulting in a profound drop in the pass rate, with many states well below an $80 \%$ pass rate (Foreman, 2017; Havrilla et al., 2018; Libner \& Kubala, 2017; Puskar et al., 2017). The reduction in the NCLEX-RN pass rate resulted in programs searching for ways to improve student success and reduce failure, on the NCLEX-RN (Havrilla et al., 2018; Robert, 2018; Shatto et al., 2019).

The body of nursing education research includes many studies on students' abilities to pass NCLEX-RN on the first attempt. Prelicensure programs of all levels have implemented admission requirements associated with passing NCLEX-RN (Quinn et al., 2018; Randolph, 2016; Robert, 2018). Prelicensure nursing programs have introduced a variety of strategies to help students succeed on NCLEX-RN, but these same strategies cannot predict if a student will fail NCLEX-RN. Recognizing if there are methods to predict if a student is likely to fail NCLEX$\mathrm{RN}$ will allow nursing programs to explore options to provide additional supports for the student at risk for failure or adjust entrance requirements. 


\section{Literature Review}

The completion of a nursing program is an intense process from meeting the entry requirements until graduation. Prerequisite courses, preadmission standardized testing, and nursing course rigor contribute to the intensity of nursing programs (Walker, 2016). Many factors such as prior course failure, poor performance on standardized examinations, and failure on classroom exams may impede students' progression through the program and may affect their ability to be successful on the NCLEX-RN (Emory, 2019).

The theoretical framework of this research study is Bandura's social learning theory of self-efficacy. Nursing students who fail NCLEX-RN may experience a loss of self-confidence and self-esteem as they watch as many of their peers pass the NCLEX-RN (Lutter et al., 2017). Nursing students who fail NCLEX-RN cite test-anxiety and fear of failure as the reasons (Lutter et al., 2017; Quinn et al., 2017). Self-efficacy is described as the individual's ability to use their self-confidence in a task to predict future success (Bonsaksen et al., 2017). Nursing students who manage to navigate nursing school from entry exams through to graduation should have the positive selfefficacy needed to be successful on the NCLEX-RN. Bandura's self-efficacy is the theoretical framework for this study to determine if there are academic predictors that might have affected the nursing student's self-efficacy as they took the NCLEX-RN.

\subsection{Nursing Programs}

Nursing programs follow a prescribed path to provide foundational knowledge for an entry-level generalist nurse. Entry-level nurses still require some skill acquisition and nursing experience (Williams et al., 2014). Entry level nurses have mixed clinical experiences, are not confident in their decision making, and are reliant on clearly defined rules to guide their practice (Benner, 2001; Williams et al., 2014). The NCLEX-RN is designed to test for the required knowledge and skills to be a safe-entry level nurse (Williams et al., 2014).

In nursing courses, most of the evaluation of the student is related to testing (Merkley, 2016). Nursing programs focus on testing and test-taking strategies to help prepare the nursing student to pass the NCLEX-RN (Merkley, 2016). The grades in nursing courses are primarily composed of scores on classroom exams and do not provide the student the opportunity to pass the course through extra credit or other assignments; this leads to a high level of rigor in nursing courses (Merkley, 2016). Testing in nursing programs follows an NCLEX style of testing, where students are expected to find the "most" correct answer or on alternate item questions (Merkley, 2016). Many students feel that prerequisite courses do not prepare them for either the rigor or the level of difficulty required to pass the NCLEX-RN (Merkley, 2016).

Many nursing programs require students to achieve benchmarks to be accepted into the program. These benchmarks include a high GPA, either overall or specifically related to the required prerequisite course work, as well as preadmission testing (Dunham \& MacInnes, 2018; Olsen, 2017; Robert, 2018; Trofino, 2013; Wambuguh et al., 2016). Throughout the program, nursing students must achieve at least a $\mathrm{C}$ or higher to pass a nursing course, have limited opportunities to repeat nursing courses, and may be required to complete a predictor exam prior to graduation (Olsen, 2017; Robert, 2018; Trofino, 2013).

\subsection{Admission Testing}

Many nursing programs require a benchmark score on a standardized preadmission test to qualify for acceptance (Olsen, 2017). The standardized examinations test for general and specific knowledge about English, mathematics, and science (Olsen, 2017). There are multiple proprietary entrance exams common to nursing programs. One is the Test of Essential Academic Skills (TEAS) (Olsen, 2017). Wambuguh et al. (2016) studied the admission criteria for a baccalaureate nursing program for over five years. One of the criteria examined was the existence of a relationship between a benchmark composite score on the TEAS entrance exam and NCLEX-RN success. This study found that students with a TEAS score of $82 \%$ or higher were more likely to pass NCLEX-RN on the first attempt than those students with a TEAS score of less than $82 \%$ (Wambuguh et al., 2016).

\subsection{Predictor Examinations}

Most nursing programs employ a standardized predictor examination not only to predict student success on NCLEX-RN but to provide a source for remediation of missed materials (Kaddoura et al., 2017). One of these is the Health Education Systems Incorporated exit exam (HESI Exit). The HESI Exit exam evaluates students' knowledge gained throughout the nursing program. The blueprint of the exam is in alignment with the NCLEXRN (Elsevier Education, 2019). Nursing program graduates who score an 850 or higher on HESI Exit have a $95 \%$ chance of passing NCLEX-RN on the first attempt (Evolve Elsevier, 2019).

\subsection{Grade Point Average}

One of the enrollment requirements for most nursing programs is an above-average grade point average (GPA) for the prerequisite or science courses (Mathew \& Aktan, 2018; Wambuguh et al., 2016). Many schools have a benchmark GPA to meet acceptable standards, but the applicant pool is so deep that the actual accepted GPA is 
much higher. To maintain a GPA of 2.5 or higher throughout the program generally requires nursing students to obtain a B or better in coursework (Tartavoulle et al., 2018). A study by Mathew and Aktan (2018) found that the higher the GPA, the greater the chance of passing NCLEX-RN on the first attempt. In their study sample, Mathew and Aktan (2018) found that 100\% of students with a GPA of 3.5 to 4.0 passed NCLEX-RN in the first attempt. Likewise, there was a $57.8 \%$ pass rate for students with a GPA of less than 3.0 (Mathew \& Aktan, 2018). Maintaining a high GPA throughout the nursing program leads to on-time graduation, which is a predictor of success on NCLEX-RN (Randolph, 2016; Sears et al., 2017; Tartavoulle et al., 2018).

\subsection{The NCLEX-RN}

Passing the NCLEX-RN is a requirement to become licensed as a registered nurse in the United States or Canada. (National Council of State Boards of Nursing, 2018). Preparation of nursing students to be safe entry-level nurses and to be ready to pass NCLEX-RN is the goal of nursing programs and nursing faculty (Shoemaker et al., 2017). In spite of the entry requirements and program rigor, the national pass rate for NCLEX-RN remains steady at about $88 \%$, with ADN program graduates having a pass rate of approximately $85 \%$ (NCSBN, 2019b). Increasing the passing standard for the NCLEX-RN occur every three years, resulting in fluctuations in program pass rates, and difficulty in maintaining appropriate remediation strategies (Puskar et al., 2017). Nursing program approval and accreditation rely on a high percentage of graduates passing NCLEX-RN on the first attempt (Accreditation Commission for the Education of Nurses, 2017). Programs that fall below a determined threshold are at risk of program closure (Florida Board of Nursing, 2018).

\section{Problem, Research Questions, Sampling, Data Analysis, Findings \\ 3.1 Problem Statement}

The problem addressed by this study is that students who are academically successful in the nursing program may still fail NCLEX-RN in the first attempt. The literature is lacking in determining if there are academic indicators that can predict if a nursing student is at risk for failure on NCLEX-RN.

The effects of failure on NCLEX-RN extend beyond the immediate result to the student, to include the nursing program and the community at large. Hospitals, healthcare centers, and the community-at-large are at risk because nursing students who fail NCLEX-RN will not be entering the workforce (Freeman \& Ali, 2017; Lutter et al., 2017 ; Trofino, 2013).

There is ample available literature connecting high-academic success with success on NCLEX-RN for firsttime test takers. Among academic indicators of NCLEX-RN passing ability, the literature includes studies about predictor exams at benchmark or higher, higher than average GPAs, and program completion within the required time frame (Czekanski et al., 2018; Quinn et al.2018). Literature also supports the use of pre-admission testing as an entry requirement, as there is a connection between pre-admission testing and NCLEX-RN success (Robert, 2018). Most nursing programs have implemented these strategies to help improve outcomes on the NCLEX-RN for first-time test takers.

In spite of these interventions, the NCLEX-RN pass rate remains steady. In the calendar year of 2018, the percentage of nursing program graduates who were successful on the NCLEX-RN was $88.29 \%$ (National Council of State Boards of Nursing, 2019). Of the percentage of graduates from associate degree in nursing (ADN) programs who pass NCLEX-RN in the first attempt, the pass rate is $85.11 \%$ (NCSBN, 2019b). Identifying students that are at high risk for failure on NCLEX-RN could support nursing faculty to explore strategies to help at-risk students succeed on NCLEX-RN, which is important to reduce unnecessary costs for the nursing student, continued viability of the nursing program, and for the community.

\subsection{Research Questions}

The purpose of this study was to determine whether a link exists between nursing student performance in program requirements and failure on the NCLEX-RN. This study used a quantitative, comparative method from data in existence to determine if there is an academic link. Acceptance into a nursing program is competitive. Potential candidates will often withdraw from prerequisite courses if they are not achieving the desired grade, or they may retake required prerequisite courses to earn a higher grade (Schutte, 2016). The same holds for the preadmission exam, which potential candidates will often take several times to meet the benchmark requirements (Dunham \& MacInnes, 2018). This study examined for a statistically significant relationship between the repetition of requirements and success or failure on NCLEX-RN.

This study strives to determine the factors that affect NCLEX-RN failure. These questions are:

RQ1: Is there an association between failure or passage of NCLEX-RN and whether or not the prerequisite science course was repeated in an associate degree nursing program?

RQ2: Is there an association between failure or passage of NCLEX-RN and whether or not the prerequisite math course was repeated in an associate degree nursing program?

RQ3: Is there an association between failure or passage on NCLEX-RN and whether or not the 
preadmission test was repeated (to achieve a $60 \%$ adjusted score) in an associate degree nursing program?

RQ4: Is there an association between failure or passage on NCLEX-RN and whether or not a score of $60 \%$ was achieved on the science portion of a preadmission test in an associate degree nursing program?

RQ5: Is there an association between failure or passage on NCLEX-RN and whether or not a score of $60 \%$ was achieved on the math portion of a preadmission test in an associate degree nursing program?

RQ6: Is there an association between failure or passage on NCLEX-RN and whether or not it was necessary to repeat a first semester (Fundamentals) course in an associate degree nursing program?

RQ7: Is there an association between failure or passage on NCLEX-RN and whether or not it was necessary to repeat the specialty course of Maternal-Family Nursing in an associate degree nursing program?

RQ8: Is there an association between failure or passage on NCLEX-RN and whether or not it was necessary to repeat the specialty course of Mental Health Nursing in an associate degree nursing program?

RQ9a: Is there an association between failure or passage on NCLEX-RN and whether or not it was necessary to repeat the first medical-surgical course in an associate degree nursing program?

RQ9b: Is there an association between failure or passage on NCLEX-RN and whether or not it was necessary to repeat the second medical-surgical course in an associated degree nursing program?

RQ10: Is there an association between failure or passage on NCLEX-RN and an overall GPA of less than 2.8 in an associate degree program?

RQ11: Is there an association between failure or passage on NCLEX-RN and a raw score of less than 850 on the Exit HESI, a predictor exam in an associate degree program?

\section{Hypotheses}

The hypotheses for this study are:

$\mathrm{H}_{1}$ : There is no association between failure or passage on NCLEX-RN and whether or not the prerequisite science course was repeated.

$\mathrm{H}_{2}$ : There is no association between failure or passage on NCLEX-RN and whether or not the prerequisite math course was repeated.

$\mathrm{H}_{3}$ : There is no association between failure or passage on NCLEX-RN and whether or not the admission test was repeated.

$\mathrm{H}_{4}$ : There is no association between failure or passage on NCLEX-RN and whether or not a score of $60 \%$ was achieved on the science portion of admission test.

$\mathrm{H}_{5}$ : There is no association between failure or passage on NCLEX-RN and whether or not a score of $60 \%$ was achieved on the mathematics portion admission test.

$\mathrm{H}_{6}$ : There is no association between failure or passage on NCLEX-RN and whether or not it was necessary to repeat a first semester (Fundamentals) nursing course.

$\mathrm{H}_{7}$ : There is no association between failure or passage on NCLEX-RN and whether or not it was necessary to repeat the Maternal-Family specialty nursing course.

$\mathrm{H}_{8}$ : There is no association between failure or passage on NCLEX-RN and whether or not it was necessary to repeat the specialty nursing course of Mental Health.

$\mathrm{H}_{9 \mathrm{a}}$ : There is no association between failure or passage on NCLEX-RN and whether or not it was necessary to repeat the first medical-surgical course.

$\mathrm{H}_{9 \mathrm{~b}}$ : There is no association between failure or passage on NCLEX-RN and whether or not it was necessary to repeat the second medical-surgical course.

$\mathrm{H}_{10}$ : There is no association between failure or passage on NCLEX-RN and an overall GPA of less than 2.8 and greater than or equal to 2.8

$\mathrm{H}_{11}$ : There is no association between failure or passage on NCLEX-RN and a raw score of 850 or higher or less than 850 on the Exit HESI.

\subsection{Population and Sample}

The data for this study is from an associate degree nursing program at one community college in Florida that admits 125 students each January and each August. The program graduates between 100 and 120 graduates each May and December, and about 12 to $17 \%$ of these graduates fail NCLEX-RN (Florida Center for Nursing, 2019; Florida Center for Nursing, 2018). This study includes all graduates in the calendar years of 2017 and 2018. The results of the NCLEX-RN are distributed quarterly from the Florida Board of Nursing and calculated for an annual pass rate of first-time test takers at the end of each calendar year.

In the calendar year of 2017, the nursing program had 224 graduates. Of the 224 graduates, 30 students failed NCLEX-RN on the first attempt. In 2018, the program was undergoing introduction of a new concept-based curriculum, requiring a teach-out of the existing program; thus, there were three graduating classes: spring, summer, and fall. A substantive change between the curriculum was the number of nursing courses increased to 13 . The 
total number of graduates was 356, with 23 failing NCLEX-RN in the first attempt.

The sample for this study consisted of the academic records for nursing program graduates from the school years of 2017-2018 and 2018-2019. These nursing students all met entry requirements, completed the nursing program requirements, and took the NCLEX-RN.

The sample size necessary to achieve a $95 \%$ confidence interval and a $5 \%$ margin of error is 155 calculated using the G*power 3.0 program (Faul et al., 2007). This would include the records of the 53 nursing students that failed the NCLEX-RN and a randomized sample of the remaining nursing student records to total 155 student records. The collected data was deidentified once it had been collected. All nursing students that graduated in the calendar years of 2017 and 2018 were eligible to participate in this study, as they met the entry and graduation requirements.

\subsection{Data Analysis and Results}

P-values greater than .05 were noted for independent variables of the prerequisite science course and math courses, similar results were found for preadmission TEAS testing related to the number of TEAS attempts and the TEAS mathematics score. The p-value for both of these independent variables was greater than .05. A p-value was less than .05 was noted for the mathematics portion of the TEAS test as the and the phi-coefficient demonstrated a weak to moderate association of greater than .1. Completion of the fundamentals course, the specialty course of Maternal-Family Nursing, and the second medical-surgical course returned p-values greater than .05 and were not significant predictors. The first medical-surgical course resulted in a p-value was less than .05 and the phicoefficient demonstrated a weak to moderate association with a level greater than .1. Overall GPA, however, returned a p-value greater than .05 indicating no significance. The HESI exit exam results returned a p-value less than .05 and the phi-coefficient demonstrated a weak to moderate association at greater than .1 (see Table 1).

\section{Research Question One/Null Hypothesis One}

RQ1: Is there an association between failure or passage of NCLEX-RN and whether or not the prerequisite science course was repeated in an associate degree nursing program?

$\mathrm{H}_{01}$ : There is no association between failure or passage on NCLEX-RN and whether or not the prerequisite science course was repeated.

The data to answer research question one was obtained from the nursing department at the study institution on the results of the NCLEX-RN. Student records that indicated a student passed NCLEX-RN were coded with a zero and those who failed NCLEX-RN were coded with a one. The data relating to the science course were obtained from the institutional review office and were coded with a one if a student completed the required course in one attempt and a zero if the student records indicate more than one attempt was needed. Coded data was entered in the SPSS program. The number of student records reviewed for this research question was 99 as many students accepted in the nursing program had prior credit for these courses from another institution and they were not excluded from this study.

Statistical analysis using Chi-squared and phi coefficient was performed using the SPSS program. The data indicated that only one student who failed NCLEX-RN and one student who passed NCLEX-RN needed to repeat a science course. Thus, $3 \%$ of the students in the sample population that failed NCLEX-RN and required more than one attempt at a prerequisite science course. The chi-square for this hypothesis had a value of 0.331 and a degree of freedom (df) of 1. The phi-coefficient is .058 and the null hypothesis is retained (Creswell, 2012).

\section{Research Question Two/Null Hypothesis Two}

RQ2: Is there an association between failure or passage of NCLEX-RN and whether or not the prerequisite math course was repeated in an associate degree nursing program?

$\mathrm{H}_{02}$ : There is no association between failure or passage on NCLEX-RN and whether or not the prerequisite mathematics course was repeated.

The data to answer research question two was obtained from the nursing department at the study institution on the results of the NCLEX-RN. Student records that indicated a student passed NCLEX-RN were coded with a zero and those who failed NCLEX-RN were coded with a one. The data relating to the prerequisite math course was obtained from the institutional review office and were coded with a zero if a student completed the required course in one attempt and a one if the student records indicate more than one attempt was needed. Coded data was entered in the SPSS program. The number of student records examined for this research question was 78 as many students accepted in the nursing program had prior credit for these courses from another institution and they were not excluded from this study.

Statistical analysis using Chi-squared and phi coefficient was performed using the SPSS program. The data indicated that only three students who failed NCLEX-RN and three students who passed NCLEX-RN needed to repeat a math course. Thus, $12.5 \%$ of the sample population that failed NCLEX-RN required more than one attempt to complete the prerequisite mathematics course. The $p$-value for this analysis was .288 . The chi-square for this hypothesis had a value of 1.128 and a degree of freedom (df) of 1 . The null hypothesis was retained. 


\section{Research Question Three/Null Hypothesis Three}

RQ3: Is there an association between failure or passage on NCLEX-RN and whether or not the preadmission test was repeated (to achieve a $60 \%$ adjusted score) in an associate degree nursing program?

$\mathrm{H}_{03}$ : There is no association between failure or passage on NCLEX-RN and whether or not the preadmission test was repeated (to achieve a $60 \%$ adjusted score).

The data for research question three was obtained from the nursing department at the study institution and reports the results of the NCLEX-RN. Student records that indicated a student passed NCLEX-RN were coded with a zero and those who failed NCLEX-RN were coded with a one. The data relating to the TEAS test was obtained from the admissions department at the study institution. Student records that indicate that a student obtained a composite score of $60 \%$ or higher on the TEAS test in one attempt were coded with a zero and a zero was used if more than one attempt was required to obtain a $60 \%$ or higher. The number of student records examined for this research question was 146 as some of the students accepted in the nursing program were accepted to the program prior to the requirement of the TEAS test.

Statistical analysis using Chi-squared and phi coefficient indicated that 11 students who failed NCLEX-RN and 15 students who passed NCLEX-RN required more than one attempt to obtain the benchmark composite score of $60 \%$. Thus, $22 \%$ of the sample population that failed NCLEX-RN, required more than one attempt to achieve the benchmark TEAS score. The p-value for this analysis was .298. The chi-square for this hypothesis had a value of 1.085 and a degree of freedom (df) of 1 . The phi-coefficient was. 086 . There is no association between dependent and independent variable of the required attempts at the TEAS test and the null hypothesis is retained.

\section{Research Question Four/Null Hypothesis Four}

RQ4: Is there an association between failure or passage on NCLEX-RN and whether or not a score of $60 \%$ was achieved on the science portion of a preadmission test in an associate degree nursing program?

$\mathrm{H}_{04}: \quad$ There is no association between failure or passage on NCLEX-RN and whether or not a score of $60 \%$ was obtained on the science portion of the preadmission test.

The data for research question four was obtained from the nursing department at the study institution on the results of the NCLEX-RN. Student records that indicated a student passed NCLEX-RN were coded with a zero and those who failed NCLEX-RN were coded with a one. The data relating to the TEAS test was obtained from the admissions department at the study institution. Student records indicated that a student obtained a science score of $60 \%$ or higher on the TEAS test were coded with a zero, and students who scored less than $60 \%$ were coded with a one. The number of student records examined for this research question was 146 as many students accepted in the nursing program were accepted to the program prior to the requirement of the TEAS test.

Statistical analysis using Chi-squared and phi coefficient indicated that 23 students who failed NCLEX-RN and 26 students who passed NCLEX-RN scored less than $60 \%$ on the science portion of the TEAS test. Thus, $47 \%$ of students from the sample population who failed NCLEX-RN, scored less than $60 \%$ on the science portion of the TEAS test. The p-value is .015. The chi-square for this hypothesis had a value of 5.919 and a degree of freedom (df) of 1. The phi-coefficient had a value of .201. There is a weak to moderate association between failure on NCLEX-RN and the null hypothesis is rejected (University of Cambridge, 2019).

\section{Research Question Five/Null Hypothesis Five}

RQ5: Is there an association between failure or passage on NCLEX-RN and whether or not a score of $60 \%$ was achieved on the math portion of a preadmission test in an associate degree nursing program?

$\mathrm{H}_{05}$ : There is no association between failure or passage on NCLEX-RN and whether or not a score of $60 \%$ was obtained on the math portion of the preadmission test.

The data for research question five was obtained from the nursing department at the study institution on the results of the NCLEX-RN. Student records that indicated a student passed NCLEX-RN were coded with a zero and those who failed NCLEX-RN were coded with a one. The data relating to the TEAS test was obtained from the admissions department at the study institution. For student records that indicate that a student obtained a score of $60 \%$ or higher on the mathematics portion of the TEAS test were coded with a zero and students who scored less than $60 \%$ were coded with a one. The number of student records examined for this research question was 146 as many some students accepted in the nursing program were in accepted to the program prior to the requirement of the TEAS test.

Statistical analysis using Chi-squared and phi coefficient indicated that six students who failed NCLEX-RN and eight students who passed NCLEX-RN required more than one attempt to obtain the benchmark composite score of $60 \%$. Thus, $12 \%$ of students that scored less than $60 \%$ on the mathematics component of TEAS test, failed NCLEX-RN. The p-value is .439. The chi-square for this hypothesis had a value of .600 and a degree of freedom (df) of 1 . The phi-coefficient is .064 There is no association between the variable and the null hypothesis is retained (Creswell, 2012).

\section{Research Question Six/Null Hypothesis Six}

RQ6: Is there an association between failure or passage on NCLEX-RN and whether or not it was necessary to repeat a first semester (Fundamentals) course in an associate degree nursing program? 
$\mathrm{H}_{06}$ : There is no association between failure or passage on NCLEX-RN and whether or not it was necessary to repeat a first semester (Fundamentals) course in an associate degree program.

The data to answer research question six were obtained from the nursing department at the study institution on the results of the NCLEX-RN. Student records that indicated a student passed NCLEX-RN were coded with a zero and those who failed NCLEX-RN were coded with a one. The data relating to the first semester (Fundamentals) course were obtained from the institutional review office and coded with a zero if a student completed the required course in one attempt and a one if the student records indicate more than one attempt was needed. The sample size for this data was slightly smaller at 144 as the nursing students who enter the program as Licensed Practical Nurses (LPNs) were not required to take this course and they were not excluded from this study.

Statistical analysis using Chi-squared and phi coefficient indicated that only one student who failed NCLEXRN and three students who passed NCLEX-RN needed to repeat the first semester (Fundamentals) course. Thus, $2 \%$ of students who failed NCLEX-RN, needed to repeat a first semester (Fundamentals) course. The p-value for this statistic was .776. The chi-square for this hypothesis had a value of 0.081 and a degree of freedom (df) of 1 . The phi-coefficient was -.024. The phi-coefficient is considered negligible and the null hypothesis is retained (Creswell, 2012).

\section{Research Question Seven/Null Hypothesis Seven}

RQ4 Is there an association between failure or passage on NCLEX-RN and whether or not it was necessary to repeat the specialty course of Maternal-Family Nursing in an associate degree nursing program?

$\mathrm{H}_{04}$ : There is no association between failure or passage on NCLEX-RN and whether or not it was necessary to repeat the specialty course of Maternal-Family Nursing in an associate degree nursing program.

The data to answer research question seven was obtained from the nursing department at the study institution on the results of the NCLEX-RN. Student records that indicated a student passed NCLEX-RN were coded with a zero and those who failed NCLEX-RN were coded with a one. The data relating to the specialty course of MaternalFamily Nursing was obtained from the institutional review office and coded with a zero if a student completed the required course in one attempt and a one if the student records indicate more than one attempt was needed.

Statistical analysis using Chi-squared and phi coefficient indicated that only three student who failed NCLEXRN and four students who passed NCLEX-RN needed to repeat the specialty course of Maternal-Family Nursing. Thus, $6 \%$ of students who failed NCLEX-RN, repeated the specialty course of Maternal-Family Nursing. The pvalue for this analysis was .630. The chi-square for this hypothesis had a value of 0.232 and a degree of freedom (df) of 1 . The phi-coefficient was 0.039 . The phi-coefficient is less than 0.1 and the null hypothesis is retained (Creswell, 2012).

\section{Research Question Eight/Null Hypothesis Eight}

RQ8: Is there an association between failure or passage on NCLEX-RN and whether or not it was necessary to repeat the specialty course of Mental Health Nursing in an associate degree nursing program?

$\mathrm{H}_{08}$ : There is no association between failure or passage on NCLEX-RN and whether or not it was necessary to repeat the specialty course of Mental Health Nursing in an associate degree nursing program.

The data to answer research question five was obtained from the nursing department at the study institution and consisted of results of the NCLEX-RN. Student records that indicated a student passed NCLEX-RN were coded with a zero and those who failed NCLEX-RN were coded with a one. The data relating to the specialty course of Mental Health Nursing was obtained from the institutional review office and coded with a zero if a student completed the required course in one attempt and a one if the student records indicate more than one attempt was needed.

Statistical analysis using Chi-squared and phi coefficient was performed using the SPSS program. None of the student records indicated failure in the specialty course of Mental Health Nursing. As there was no variation in the coded data, statistical analysis was not performed.

\section{Research Question Nine a/Null Hypothesis Nine a}

RQ9a: Is there an association between failure or passage on NCLEX-RN and whether or not it was necessary to the first medical-surgical course in an associate degree nursing program?

$\mathrm{H}_{09 \mathrm{a}}$ : There is no association between failure or passage on NCLEX-RN and whether or not it was necessary to repeat the first medical-surgical course.

The data to answer research question nine was obtained from the nursing department at the study institution and consisted of results of the NCLEX-RN. Student records that indicated a student passed NCLEX-RN were coded with a zero and those who failed NCLEX-RN were coded with a one. The data relating to the medicalsurgical course was obtained from the institutional review office and coded with a zero if a student completed the required course in one attempt and a one if the student records indicate more than one attempt was needed. Coded data was entered in the SPSS program.

Statistical analysis using Chi-squared and phi coefficient indicated that ten students who failed NCLEX-RN and five students who passed NCLEX-RN needed to repeat the second semester medical-surgical course. Thus, $19 \%$ of students who failed NCLEX-RN, required more than one attempt at the second semester medical-surgical 
course. The p-value for this analysis was .005. The chi-square for this hypothesis had a value of 7.783 and a degree of freedom (df) of 1 . The phi-coefficient was 0.224 . Additional statistical data of a likelihood ratio of 7.318 and an approximate significance of .005 the finding is likely accurate (Field, 2018). A phi-coefficient of 0.224 indicates a moderate association between the dependent variable and the independent variable of the need to repeat the medical-surgical course in the second semester (Creswell, 2012).

\section{Research Question Nine b/Null Hypothesis Nine b}

RQ9b: Is there an association between failure or passage on NCLEX-RN and whether or not it was necessary to repeat the second medical-surgical course in an associate degree nursing program?

$\mathrm{H}_{0 \mathrm{~b} 9}$ : There is no association between failure or passage on NCLEX-RN and whether or not it was necessary to repeat the second medical-surgical course.

The data to answer research question nine was obtained from the nursing department at the study institution and consisted of results of the NCLEX-RN. Student records that indicated a student passed NCLEX-RN were coded with a zero and those who failed NCLEX-RN were coded with a one. The data relating to the medicalsurgical course was obtained from the institutional review office and coded with a zero if a student completed the required course in one attempt and a one if the student records indicate more than one attempt was needed. Coded data was entered in the SPSS program.

Statistical analysis using Chi-squared and phi coefficient indicated that five students who failed NCLEX-RN and four students who passed NCLEX-RN needed to repeat the final semester medical-surgical course. Thus, $9 \%$ of students who failed NCLEX-RN, required more than one attempt at the final semester medical-surgical course. The p-value for this analysis was .164. The chi-square for this hypothesis had a value of 1.983 and a degree of freedom (df) of 1 . The phi-coefficient was 0.112 . There is no association identified and the null hypothesis is retained.

\section{Research Question Ten/Null Hypothesis Ten}

RQ7: Is there an association between failure or passage on NCLEX-RN and an overall GPA of less than 2.8 in an associate degree program?

$\mathrm{H}_{07}$ : There is no association between failure or passage on NCLEX-RN and an overall GPA of less than 2.8 and greater than or equal to 2.8

The data to answer research question ten was obtained from the student records that indicated a student passed NCLEX-RN and were coded with a zero and those who failed NCLEX-RN were coded with a one. The data relating to the GPA was obtained from the institutional review office and coded with a zero if the records indicated an overall GPA of greater than 2.8 and a one if the student records indicated the overall GPA was less than 2.8. Coded data was entered in the SPSS program.

Statistical analysis using Chi-squared and phi coefficient indicated that ten students who failed NCLEX-RN and nine students who passed NCLEX-RN had an overall GPA of less than 2.8 . Thus, $19 \%$ of students who failed NCLEX-RN had an overall GPA of less than 2.8. The p-value for this analysis was .07. The chi-square for this hypothesis had a value of 3.272 and a degree of freedom (df) of 1 . There is no association between the dependent and independent variable and the null hypothesis is retained.

\section{Research Question 11/Null Hypothesis 11}

RQ11: Is there an association between failure or passage on NCLEX-RN and a raw score of less than 850 on the Exit HESI, a predictor exam in an associate degree program?

$\mathrm{H}_{11}$ : There is no association between failure or passage on NCLEX-RN and a raw score of 850 or higher or less than 850 on the Exit HESI.

The data to answer research question eleven were obtained from the student records that indicated a student passed NCLEX-RN and were coded with a zero and those who failed NCLEX-RN were coded with a one. The data relating to the HESI was obtained from the nursing department records from the vendor and coded with a zero if the records indicated the student scored 850 or higher on the HESI Exit exam and a 1 if the student scored less than 850. Coded data was entered in the SPSS program.

Statistical analysis using Chi-squared and phi coefficient indicated that 34 students who failed NCLEX-RN and 46 students who passed NCLEX-RN had a HESI Exit score of less than 850 . Thus, $64 \%$ of students who failed NCLEX-RN had a HESI Exit score of less than 850 . The p-value for this analysis is .028 . The chi-square for this hypothesis had a value of 4.821 and a degree of freedom (df) of 1 . The phi-coefficient was 0.177 . A phi-coefficient of 0.196 indicates a weak to moderate association between the dependent variable and the independent variable of the HESI Exit (Creswell, 2012). The null hypothesis is rejected.

\section{Conclusion}

The intent of this study was to determine if a link existed between nursing student performance in program requirements and failure on the NCLEX-RN. The theoretical framework focused on Bandura's theory of selfefficacy to determine if nursing students' failure on NCLEX-RN could be related to a low self-efficacy as determined by the need to repeat a nursing program requirement. Each research question and null hypothesis was 
analyzed to determine what conclusions the research reached.

The statistical analysis resulted in a weak to moderate association between some academic factors and passage or failure on NCLEX-RN. The academic factors analyzed that produced a weak to moderate association between the independent and dependent variable included: Scoring less than 60 on the science portion of the TEAS exam; The need to repeat the first medical-surgical nursing course; Scoring less than 850 on HESI Exit.

Each of the analysis indicate there is a relationship to the failure or passage on NCLEX-RN. Some of the academic factors studied did not demonstrate an association between these factors and passage or failure of NCLEX-RN. The academic factors relating to the admission requirements that had no significance were the need to repeat a prerequisite science or mathematics course, the number of attempts at the preadmission TEAS exam, and the score on the mathematics portion of the TEAS exam. The academic factors relating to program progression that had no significance were the need to repeat the nursing course of Fundamentals, Maternal-family nursing, Mental Health nursing, or the second medical-surgical nursing course. The academic factor relating to program requirements that had no significance was the overall GPA.

The nursing shortage is predicted to reach critical levels in the next few years, and it is important for nursing programs to admit nursing students that can be successful on NCLEX-RN (Benner et al., 2010; Quinn et al., 2018). The purpose of this study was to determine if any of these entry requirements or nursing course repetition leads towards understanding why nursing school graduates fail NCLEX-RN. As a result of this study, there are several findings that may impact nursing programs.

\section{References}

Accreditation Commission for the Education of Nurses. (2017). http://www.acenursing.net/manuals/sc2017 A.pdf Benner, P. (2001). From novice to expert: Excellence and power in clinical nursing practice (2 ed.). Upper Saddle River, NC: Prentice-Hall.

Benner, P., Sutphen, M., Leonard, V., \& Day, L. (2010). Educating nurses: A call for radical transformation. San Francisco, CA: Jossey-Bass.

Bonsaksen, T., Sadeghi, T., \& Thorrisen, M. (2017). Associations between self-esteem, general self-efficacy, and approaches to studying in occupational therapy students: A cross-sectional study. Occupational Therapy in Mental Health, 33(4), 326-341. https://doi.org/10.1080/0164212X.2017.1295006

Creswell, J. (2012). Educational research: Planning, conducting, and evaluating quantitative and qualitative research ( $4^{\text {th }}$ ed.). Boston, MA: Pearson.

Czekanski, K., Mingo, S., \& Piper, L. (2018). Coaching to NCLEX-RN Success: A postgraduation intervention to improve first-time pass rates. Journal of Nursing Education, 57(9), 561-565. https://doi.org/10.3928/01484834-20180815-10

Dunham, M., \& MacInnes, J. (2018). Relationship of multiple attempts on an admissions examination to early program performance. Journal of Nursing Education, 57(10), 578-583. https://doi.org/10.3928/0148483420180921-02

Emory, J. (2019). Exploring NCLEX failures and standardized assessments. Nurse Educator, 44(3), 142-146. https://doi.org/10.1097/NNE.0000000000000601

Evolve Elsevier. (2019). HESI exit exam: Using benchmarks and testing policies to predict NCLEX-RN exam pass rates. https://evolve.elsevier.com/education/hesi/resources-hesi-exit-exam-predict-nclex-rn-pass-rate/

Faul, F., Erdfelder, E., Lang, A. G., \& Buchner, A. (2007). G*Power 3: A flexible statistical power analysis program for the social, behavioral, and biomedical sciences. Behavior Research Methods, 29, 175-191. https://10.3758/bf03193146

Field, A., (2018). Discovering statistics using IBM SPSS statistics: North American edition, $5^{\text {th }}$ ed. Thousand Oaks, CA: Sage edge.

Florida Board of Nursing. (2018). Practical and registered nursing programs. https://floridasnursing.gov/licensing/practical-and-registered-nurse-education-program/

Florida Center for Nursing (2019). Review of Florida nurse education program graduate passage rates on the National Council of State Boards of Nursing licensure examination: Calendar year 2018. https://floridasnursing.gov/forms/nclex-passage-rates-analysis.pdf

Florida Center for Nursing (2018). Review of Florida nurse education program graduate passage rates on the National Council of State Boards of Nursing licensure examination: Calendar year 2017. https://floridasnursing.gov/forms/nclex-passage-rates-2017.pdf

Foreman, S. (2017). The accuracy of state NCLEX-RN passing standards for nursing programs. Nurse Education Today, 52, 81-86. http://dx.doi.org/10.1016/j.nedt.2017.02.019

Freeman, J. C., \& All, A. (2017). Nursing Education Perspectives, 38(2), 69-74. http://dx.doi.org/10.1097/01.NEP.0000000000000089

Glasgow, M., Deher, H., \& Schreiber, J. (2019). Standardized testing in nursing education: Preparing students for NCLEX-RN and practice. Journal of Professional Nursing 35(6), 440-446. 
https://doi.org/10.1016/j.profnurs.2019.04.012

Havrilla, E., Zbegner, D., \& Victor, J. (2018). Exploring predictors of NCLEX-RN success: One school's search for excellence. Journal of Nursing Education, 57(9), 554-556. https://doi.org/10.3928/01484834-2018081508

Kaddoura, M., Flint, E., Van Dyke, O., Yank, Q., \& Chiang, L. (2017). Academic and demographic predictors of NCLEX-RN pass rates in first- and second-degree accelerated BSN programs. Journal of Professional Nursing, 33(3), 229-240. https://doi.org/10.1016/j.profnurs.2016.09.005

Libner, J., \& Kubala, S. (2017). Improving program NCLEX pass rates: Strategies from one state board of nursing. Nursing Education Perspectives, 38(6), 325-329. https://doi.org/10.1097/01.NEP.0000000000000219

Lutter, S. L., Thompson, C. W., \& Condon, M. C. (2017). Tutoring for success: Empowering graduate nurses after failure on the NCLEX-RN. Journal of Nursing Education, 56(12), 758-761. http://dx.doi.org/10.3928/01484834-20171120-11

Mathew, L., \& Aktan, N. (2018). Factors associated with NCLEX-RN success of graduates from an undergraduate nursing program. Journal of Nursing Practice Applications and Reviews of Research, 8(2). 50-59. https://doi.org/10.13178/jnparr.2018.0802.0808

Merkley, B. R. (2016). Student nurse attrition: A half-century of research. Journal of Nursing Education and Practice, 6(3), 71-75. https://doi.org/10.5430/jnep.v6n3p 71

National Council of State Boards of Nursing. (2018). Guiding principles. https://www.ncsbn.org/1325.htm

National Council of State Boards of Nursing (NCSBN). (2019). Candidate performance report. https://www.ncsbn.org/1223.htm

Olsen, J. (2017). Integrative review of admission factors related to associate degree nursing program success. Journal of Nursing Education, 56(2), 85-93. https://doi.org/10.3928/01484834-20170123-05

Puskar, K., Rudolph, M., \& Shi, X. (2017). NCLEX RN exam: A university school of nursing case study of preparation strategies. Journal of Nursing Education and Practice, 7(11), 37-43. https://doi.org/10.5430/jnep.v7n11p37

Quinn, B., Smolinski, M., \& Bostain Peters, A. (2018). Strategies to improve NCLEX-RN success: A review. Teaching and Learning in Nursing, 13, 18-26. https://doi.org/10.1016/j.teln.2017.09.002

Ralph, N., Graham, C., Beccaria, L., \& Rogers, C. (2019). Entry requirements in nursing: Results from a national survey of nurse academics on entry requirements in Australian Bachelor of Nursing programs. Collegian, 26, 140-145. https://doi.org/10.1016/j.colegn.2018.06.005

Randolph, P. (2016). Standardized testing practices: Graduation and NCLEX pass rates. Journal of Professional Nursing, 33(3), 224-228. http://dx.doi.org/10.1016/j.profnurs.2016.09.002

Robert, N. (2018). Predictor of program completion and NCLEX-RN success in an associate degree nursing program. Nursing Education Perspectives, 39(1), 38-39. https://doi.org/10.1097/01.NEP.0000000000000237

Schlairet, M., \& Rubenstein, C. (2019). Senior NCLEX-RN coaching model. Nurse Educator, 44(5), 250-254. https:/doi.org/10.1097/NNE.0000000000000644

Schutte, A. (2016). Who is repeating anatomy? Trends in an undergraduate anatomy course. Anatomical Sciences Education, 9(2), 171-178. https://doi.org/10.1002/ase.1553

Sears, N., Othman, M., O’Neil, L., \& Hopman, W. (2017). Canadian NCLEX-RN outcomes: A two-year crosssectional exploratory study in Ontario. Journal of Nursing Education and Practice, 7(10), 36-45. https://doi.org/10.5430/jnep.v7n10p36

Shatto, B., Shagavah, A., Krieger, M., Lutz, L., Duncan, C., \& Wagner, E. (2019). Active learning outcomes on NCLEX-RN or standardized predictor examinations: An integrative review. Journal of Nursing Education, 58(1), 42-46. https://doi.org/10.3928/01484834-20190103-07

Shoemaker, J., Chavez, R., Keane, P., Butz, S., \& Yowler, S. (2017). Effective utilization of computerized curricular assist tools in improving NCLEX-RN pass rates for a baccalaureate nursing program. Computers, Informatics, Nursing, 35(4), 194-200. https://doi.org/10.1097/CIN.0000000000000311

Snavely, T. M. (2016). A brief economic analysis of the looming nursing shortage in the United States. Nursing Economic\$, 34(2), 98-100. PMID: 27265953.

Tartavoulle, T., Adorno, M., Garbee, D., Kensler, P., Manning, J., \& Pierce, S. (2018). Predictors of success in BSN students. International Journal of Nursing Education Scholarship, 15(1). https://doi.org/10.1515/ijnes2017-0028

Trofino, R. (2013). Relationship of associate degree nursing program criteria with NCLEX-RN success: What are the best predictors in a nursing program of passing the NCLEX-RN the first time? Teaching and Learning in Nursing, 8, 4-12. http://dx.doi.org/10.1016/j.teln.2012.08.001

University of Cambridge (2019). Rules of thumb on magnitudes of effect sizes. Retrieved from: https://imaging.mrc-cbu.cam.ac.uk/statswiki/FAQ/effectSize

Walker, L. P. (2016). A bridge to success: A nursing student success strategies improvement course. Journal of Nursing Education, 55(8), 450-453. https://doi.org/10.3928/01484834-20160715-05 
Wambuguh, O., Eckfield, M., \& Hofwegen, L. (2016). Examining the importance of admissions criteria in predicting nursing program success. International Journal of Nursing Education Scholarship, 13(1), 87-96. https://doi.org/10.1515/ijnes-2015-0088

Wessel, K. (2017). How an aging population is transforming nursing. Home Healthcare Now, 36(4) 221-223. https://doi.org/10.1097/NHH.0000000000000543

Williams, N., Kim, D., Dickinson, P., \& Woo, A. (2014). NCLEX and entry-level nurse characteristics. Journal of Nursing Regulation, 5(2), 45-49. https://doi.org/10.1016/S2155-8256(15)30082-X

Table 1

Statistical Analysis of Independent Variables as Compared to the Dependent Variable.

\begin{tabular}{|c|c|c|c|c|c|}
\hline & $\begin{array}{ll}\text { Number } & \text { of } \\
\text { Participants } & \end{array}$ & $\begin{array}{l}\mathrm{p} \text { - } \\
\text { value }\end{array}$ & $\begin{array}{l}\text { Chi- } \\
\text { Square }\end{array}$ & $\underline{\mathrm{d}(\mathrm{f})}$ & Phi- \\
\hline Prerequisite science course & 99 & .565 & .331 & 1 & .058 \\
\hline Prerequisite mathematics course & 78 & .288 & 1.128 & 1 & .120 \\
\hline TEAS attempts & 146 & .298 & 1.085 & 1 & .086 \\
\hline TEAS: Math & 146 & .439 & .600 & 1 & .064 \\
\hline TEAS: Science & 146 & .015 & 5.919 & 1 & .201 \\
\hline First semester (Fundamentals) course & 146 & .776 & .081 & 1 & -.024 \\
\hline Maternal-Family nursing course & 154 & .630 & .232 & 1 & .039 \\
\hline Medical-surgical course, first course & 155 & .005 & 7.783 & 1 & .224 \\
\hline $\begin{array}{l}\text { Medical-surgical course, second } \\
\text { course }\end{array}$ & 155 & .164 & 1.938 & 1 & .112 \\
\hline Overall GPA & 155 & .07 & 3.272 & 1 & .145 \\
\hline HESI Exit & 154 & .028 & 4.821 & 1 & .177 \\
\hline
\end{tabular}

